\title{
The effect of ambient particle matters on hospital admissions for cardiac arrhythmia: a multi-city case-crossover study in China
}

\author{
Qiwen Zheng ${ }^{1+}$, Hui Liu ${ }^{1,2+}$, Jun Zhang ${ }^{3^{*}}$ and Dafang Chen ${ }^{1^{*}}$
}

\begin{abstract}
Background: The relationship between particle matters (PMs) and cardiac arrhythmia has been investigated in numerous studies. However, evidence from developing countries is limited. The aim of this study was to evaluate the association between ambient PMs and hospital admissions for cardiac arrhythmia in China and to examine the potential effect modifiers.

Methods: A time-stratified case-crossover analysis was conducted in 26 large Chinese cities. In total, we identified 175,265 hospital admissions for cardiac arrhythmia between January 2014 and December 2015 from electronic hospitalization summary reports. Conditional logistic regression was performed to estimate the percentage changes in cardiac arrhythmia admissions in relation to interquartile range increases in air pollutants. Age, gender and prespecified comorbid health conditions including hypertension, diabetes, congestive heart failure and hyperlipidemia were stratified to evaluate susceptibility factors.
\end{abstract}

Results: PMs levels were positively associated with the number of hospital admissions for cardiac arrhythmia. Both PM 2.5 and $\mathrm{PM}_{10}$ had the strongest impact on lag 2 days. An interquartile range increase in $\mathrm{PM}_{2.5}\left(47.5 \mu \mathrm{g} / \mathrm{m}^{3}\right)$ and $\mathrm{PM}_{10}(76$. $\left.9 \mathrm{\mu g} / \mathrm{m}^{3}\right)$ concentrations on lag 2 days was associated with increments of $2.09 \%(95 \% \mathrm{Cl}, 1.58-2.60 \%)$ and $2.33 \%(95 \% \mathrm{Cl}, 1$. 68-2.97\%) in hospital admission for cardiac arrhythmia, respectively. Evidence of effect modification by age and comorbid diabetes was observed. The elderly (> 65 years) and patients with comorbid diabetes were more likely to be hospitalized for cardiac arrhythmia following exposure to high levels of PMs.

Conclusions: This study found an increased risk of arrhythmia admissions associated with $\mathrm{PM}_{2.5}$ and $\mathrm{PM}_{10}$ levels among 26 Chinese cities. The associations of PMs with arrhythmia admissions were stronger in aged population and people with diabetes.

Keywords: Air pollution, Particle matter, Cardiac arrhythmia, Hospitalization, Case-crossover

\section{Background}

Over the past decades, with the development of industry and economy, air pollution contributes to a considerable public concern worldwide, especially in developing countries, in which ambient particle matters (PMs) were considered as the predominant pollutant. Ambient PMs was the fifth-ranking mortality risk factor in 2015,

\footnotetext{
* Correspondence: jun_zhang@bjmu.edu.cn; dafangchen@bjmu.edu.cn

${ }^{\dagger}$ Qiwen Zheng and Hui Liu contributed equally to this work.

${ }^{3}$ Department of Neurology, Peking University People's Hospital, No.11 South Xizhimen Street, Xicheng District, Beijing 100044, China

${ }^{1}$ Department of Epidemiology and Biostatistics, School of Public Health, Peking

University, No.38 Xueyuan Road, Haidian District, Beijing 100191, China
}

Full list of author information is available at the end of the article accounting for $7.6 \%$ global deaths and $4.2 \%$ DALYs [1]. In China, it was ranked the forth risk factor for disease burden, leading to more than 0.9 million premature deaths annually [2].

Cardiac arrhythmia consists of a group of complex conditions which is related to the risks of cardiovascular complications and sudden deaths [3]. Increasing evidence revealed the facts that air pollution is associated with the risk of hospital admission, emergency room visits and mortality from cardiovascular causes [4-7]. Deeply knowing the association between PMs and specific cardiovascular endpoint is proving of great importance to better understand the physio pathological mechanisms, aiding

(C) The Author(s). 2018 Open Access This article is distributed under the terms of the Creative Commons Attribution 4.0 International License (http://creativecommons.org/licenses/by/4.0/), which permits unrestricted use, distribution, and 
the development of personalized interventions and the making of healthcare policies.

Several epidemiological studies have suggested that exposure to ambient particle matters might be responsible for cardiac arrhythmia [8-11]. Recently, a meta-analysis also demonstrated the temporal association between $\mathrm{PM}_{2.5}, \mathrm{PM}_{10}$ and arrhythmia hospitalization or mortality with the risk ratio 1.015 per $10 \mu \mathrm{g} / \mathrm{m}^{3}$ and 1.009 per $10 \mu \mathrm{g} / \mathrm{m}^{3}$, respectively [12]. However, most of the previous studies which assessed the association between particle matters and cardiac arrhythmias were carried out in North America, Western Europe and East Asia. These findings may not be applicable to Mainland of China, because of the different ambient air pollutant mixtures, weather patterns, health status and population susceptibility. Furthermore, although one study has recently been conducted in China to explore the relationship between air pollution and cardiac arrhythmia [13], the evidence was still limited in China as data were often restrained from individual cities, introducing uncertainties to results in external validation. In addition, evidence from previous studies has shown that persons with comorbidities may be at increased risk of cardiovascular morbidity and mortality $[14,15]$, but little is known about the potentially sensitive groups in Chinese populations.

Therefore, the primary objective of this study was to explore the association between ambient particle matters and hospital admissions for cardiac arrhythmia in 26 large Chinese cities during 2014-2015, by using a time-stratified case-crossover design. The secondary objective was to examine whether subjects with specific comorbid health conditions were more susceptible to particle matters.

\section{Methods}

\section{Study design}

A time-stratified case-crossover study were performed to investigate the association between PMs and daily cardiac arrhythmia hospital admissions [16]. In this approach, the cases played a role as their own controls, where the exposure experience at different time periods (before or after the case period) were compared. For each case of cardiac arrhythmia, the control days were chosen on a fixed time stratum, typically the days falling in the same city on the same day of week and within the same calendar month as the index day (the day of hospitalization for cardiac arrhythmia). By using this study design, precise control for long-term trend, day of week and some other slowly changing individual-level factors such as age, gender, race, smoking status, educational background and lifestyles were achieved.

\section{Hospital admissions data}

The daily hospital admissions for cardiac arrhythmia in 26 cities during the study period were obtained from electronic hospitalization summary reports (HSRs) of the top-ranked hospitals (Grade 3A) in care, safety and quality as evaluated by the National Hospital Performance Project of the National Healthcare Data Center of China. More than 15 million HSRs were collected for this project during 2014 to 2015. The detailed description of this project has been published previously [17]. The standard HSRs includes information on basic demographics, dates of admission and discharge, hospitalization diagnoses (one principle diagnosis and ten comorbidities) and their corresponding International Classification of Diseases, 10th Revision (ICD-10) codes, treatments, outcomes of hospitalization and financial costs.

The primary outcome of our study is cardiac arrhythmia daily admission counts. We used ICD-10 codes to identify arrhythmia-related admissions between January 1, 2014 and December 31, 2015 in each study city, and then transformed them into daily counts for further modeling analysis. These codes included I44 (atrioventricular and left bundle-branch block), I45 (other conduction disorders), I46 (cardiac arrest), I47 (paroxysmal tachycardia), I48 (atrial fibrillation and flutter), and I49 (other cardiac arrhythmia). Patients aged less than 18 years old were excluded from the present study. In total, 175,265 hospitalization admissions were identified from 26 large cities (shown in Additional file 1: Figure S1) in China during the study period.

Age, gender and prespecified selected comorbid health conditions were the effect modifiers of interest. ICD-10 codes were used to identify the comorbidities in addition to a primary diagnosis of cardiac arrhythmia for each subject. The comorbidities examined in this study were defined as follows: diabetes mellitus (E10-E14), hypertensive diseases (I10-I13, I15), heart failure (E50) and hyperlipidemia (E78).

\section{Environmental data}

Daily average concentrations of air pollutants in 26 Chinese cities were obtained from the National Urban Air Quality Real-time Publishing Platform (http://106.37.208.233:20035/, with detailed description in Additional file 1). In brief, the system fulfills the quality assurance and quality control mandates of the Chinese government through its ambient air-monitoring stations. These stations provide hourly air pollution data to the system. The air pollutants in this study included particulate matter with an aerodynamic diameter less than $2.5 \mu \mathrm{m}\left(\mathrm{PM}_{2.5}\right)$, particulate matter with an aerodynamic diameter less than $10 \mu \mathrm{m}\left(\mathrm{PM}_{10}\right)$, carbon monoxide $(\mathrm{CO})$, nitrogen dioxide $\left(\mathrm{NO}_{2}\right)$ and sulfur dioxide $\left(\mathrm{SO}_{2}\right)$. The daily (24-h) mean concentrations of pollutants averaged across all the stations in a given city were used as the reading for that city on that day. In addition, meteorological data including 24 -h average temperature $\left({ }^{\circ} \mathrm{C}\right)$ and relative humidity (\%) for each city in the study were obtained from Chinese Meteorological Bureau. 


\section{Statistical analysis}

All statistical analyses were conducted using R (V.3.3.3, R Development Core Team). Data are presented as mean \pm $\mathrm{SD}$, median (interquartile range), or absolute number and percentages, as appropriate. Spearman's correlation analyses were performed to examine the relationship between air pollutant variables. Conditional logistic regression was used to explore the associations between PM and cardiac arrhythmia. The distributed lag non-linear models with three degrees of freedom in the natural cubic splines and a maximum lag of 3 days were applied to adjust the delayed and non-linear effects of temperature and humidity [18]. Interactions between meteorology and cities were included in the model to control possible confounding factors, including baseline prevalence of cardiac arrhythmia and weather conditions in each city. Public holidays were also incorporated. Both single-day lag structure (Lag0 to Lag5) and multiple-day lag structure (Lag0-2, Lag0-3, Lag0-4 and Lag0-5) were employed in this analysis to examine the temporal association between PMs and arrhythmia. In addition, a smoothing function was applied to graphically analyze the exposure-response association between PMs concentration and cardiac arrhythmia hospitalizations.

In order to examine potential confounding factors by other air pollutants, two-pollutant models adjusted for $\mathrm{CO}, \mathrm{NO}$ and $\mathrm{SO}_{2}$ were applied. Stratification analyses by age, gender and prespecified comorbidities to explore the potential individual level effect modifiers of particle matters were also conducted using the above models. Subgroup analyses were compared using a Z-test [19]. The results are expressed as the percentage change and 95\% confidence interval (CI) in the daily cardiac arrhythmia hospital admissions per interquartile range (IQR) increase in PMs concentration. The reported significance levels were all two-sided, with statistical significance set at 0.05 .

\section{Results}

A total of 175,265 patients whose principle diagnosis was cardiac arrhythmia during their hospitalization were included in this study. The basic characteristics of the study population were listed in Table 1 . The median age was 59.0 (IQR: $48.0-70.0$ ) years old with $50.6 \%$ male patients. Among all the prespecified comorbid health conditions, hypertension was the largest, with $37 \%$ of the admissions for cardiac arrhythmia having a comorbidity of hypertension. Other comorbid health conditions included were diabetes mellitus, hyperlipidemia and congestive heart failure, with 11.4, 13.7 and $10.6 \%$ of total hospital cardiac arrhythmia admission, respectively. The descriptive statistics for the cardiac arrhythmia hospital admissions, air pollutants and meteorological variables were listed in Table 2. There was an average of 240 daily
Table 1 Characteristics of the study population $(n=175,265)$

\begin{tabular}{ll}
\hline & No. (\%) \\
\hline Demographic & \\
Gender & \\
Male & $88,760(50.6 \%)$ \\
Female & $86,505(49.4 \%)$ \\
Age & \\
$\quad<65$ years old & $112,403(64.1 \%)$ \\
$\geq 65$ years old & $62,862(35.9 \%)$ \\
Comorbid health condition & \\
Hypertension & \\
$\quad$ With & $64,786(37.0 \%)$ \\
$\quad$ Without & $110,479(63.0 \%)$ \\
Diabetes & \\
$\quad$ With & $19,947(11.4 \%)$ \\
$\quad$ Without & $155,318(88.6 \%)$ \\
Hyperlipidemia & \\
With & $23,957(13.7 \%)$ \\
Without & $151,308(86.3 \%)$ \\
Congestive heart failure & \\
With & $18,529(10.6 \%)$ \\
Without & $156,736(89.4 \%)$ \\
\hline
\end{tabular}

hospital admissions for cardiac arrhythmia in the 26 Chinese cities across the study period. The mean particle matters level during the study period was $106.8 \mu \mathrm{g} / \mathrm{m}^{3}$ for $\mathrm{PM}_{10}$ and $63.5 \mu \mathrm{g} / \mathrm{m}^{3}$ for $\mathrm{PM}_{2.5}$. Mean daily concentrations of $\mathrm{SO}_{2}, \mathrm{NO}_{2}$ and $\mathrm{CO}$ were: $29.6 \mu \mathrm{g} / \mathrm{m}^{3}, 44.1 \mu \mathrm{g} /$ $\mathrm{m}^{3}$ and $1.15 \mathrm{mg} / \mathrm{m}^{3}$, respectively. Spearman's correlation analyses showed that the concentrations of $\mathrm{PM}_{2.5}$ and $\mathrm{PM}_{10}$ were highly correlated (Table $3, r=0.87$ ). Meanwhile, $\mathrm{SO}_{2}, \mathrm{NO}_{2}$ and $\mathrm{CO}$ were moderately correlated with $\mathrm{PM}_{2.5}$ and $\mathrm{PM}_{10}(r=0.61-0.68)$.

Figure 1 depicted the exposure-response curves for daily concentration of $\mathrm{PM}_{2.5}$ and $\mathrm{PM}_{10}$ with hospitalization for cardiac arrhythmia. The concentration-response relationship appeared to be linear and positive without any thresholds. Table 4 presented the percentage change in daily admission for cardiac arrhythmia associated with an IQR increase in particle matters concentrations for different lag structures. For $\mathrm{PM}_{2.5}$, the single-lag model estimated positive and significant associations on lag $0,1,2$ and 3 days. Consistent results were observed between $\mathrm{PM}_{10}$ and cardiac arrhythmia. Both $\mathrm{PM}_{2.5}$ and $\mathrm{PM}_{10}$ had the strongest impact on lag 2 days. An IQR increment in $\mathrm{PM}_{2.5}$ and $\mathrm{PM}_{10}$ concentrations on lag 2 days was associated with increments of $2.09 \%$ (95\%CI, $1.58-2.60 \%$ ) and $2.33 \%$ (95\%CI, 1.68-2.97\%) in hospital admission for cardiac arrhythmia, respectively. The cumulative increase for arrhythmia admission due to $\mathrm{PM}_{2.5}$ was $2.93 \%$ across three 
Table 2 Distribution of daily cardiac arrhythmia hospital admissions, meteorological data and air pollutants in 26 Chinese cities, 2014-2015

\begin{tabular}{|c|c|c|c|c|c|c|c|}
\hline \multirow[t]{2}{*}{ Variable } & \multirow[t]{2}{*}{ Mean \pm SD } & \multirow[t]{2}{*}{ Minimum } & \multicolumn{3}{|c|}{ Percentile } & \multirow[t]{2}{*}{ Maximum } & \multirow[t]{2}{*}{ IQR } \\
\hline & & & 25th & 50th & 75th & & \\
\hline $\mathrm{PM}_{2.5}\left(\mu \mathrm{g} / \mathrm{m}^{3}\right)$ & $63.5 \pm 50.6$ & 5.1 & 31.5 & 49.4 & 79.0 & 897.5 & 47.5 \\
\hline $\mathrm{PM}_{10}\left(\mu \mathrm{g} / \mathrm{m}^{3}\right)$ & $106.8 \pm 71.9$ & 7.4 & 58.3 & 89.4 & 135.2 & 977.3 & 76.9 \\
\hline $\mathrm{SO}_{2}\left(\mu \mathrm{g} / \mathrm{m}^{3}\right)$ & $29.6 \pm 32.6$ & 1.9 & 11.4 & 18.8 & 33.6 & 316.9 & 22.2 \\
\hline $\mathrm{NO}_{2}\left(\mu \mathrm{g} / \mathrm{m}^{3}\right)$ & $44.1 \pm 19.4$ & 4.5 & 30.0 & 40.2 & 54.1 & 175.8 & 24.1 \\
\hline $\mathrm{CO}\left(\mathrm{mg} / \mathrm{m}^{3}\right)$ & $1.15 \pm 0.63$ & 0.14 & 0.76 & 0.99 & 1.32 & 8.41 & 0.56 \\
\hline Temperature $\left({ }^{\circ} \mathrm{C}\right)$ & $14.5 \pm 10.9$ & -25.7 & 7.0 & 16.4 & 23.3 & 35.5 & 16.3 \\
\hline Relative humidity (\%) & $69.2 \pm 33.2$ & 8 & 53 & 69 & 80 & 97 & 27 \\
\hline Daily arrhythmia admissions & $240.1 \pm 129.8$ & 2 & 93 & 270 & 320 & 555 & 227 \\
\hline
\end{tabular}

$S D$ standard deviation, IQR interquartile range

days, and the effect due to $\mathrm{PM}_{10}$ was $3.58 \%$ across four days. An IQR increase in $\mathrm{NO}_{2}$ and $\mathrm{CO}$ concentrations on lag2 day corresponded with a $2.45 \%(95 \% \mathrm{CI}, 1.73-3.17 \%)$ and $2.79 \%(95 \% \mathrm{CI}, 2.20-3.39 \%)$ increases in cardiac arrhythmia admissions, respectively. However, the association between $\mathrm{SO}_{2}$ and cardiac arrhythmia admissions is insignificant $(-0.80 \%, 95 \mathrm{CI},-1.42-0.18 \%, p=0.066)$.

In the two-pollutant models (Table 5), the effect of $\mathrm{PM}_{2.5}$ and $\mathrm{PM}_{10}$ on cardiac arrhythmia admissions was slightly stronger when controlling for $\mathrm{SO}_{2} . \mathrm{PM}_{2.5}$ showed consistent and significant associations with arrhythmia when adjusted for $\mathrm{CO}$ and $\mathrm{NO}_{2}$. Nevertheless, the association of arrhythmia admissions with $\mathrm{PM}_{10}$ was insignificant and even close to null after controlling for $\mathrm{NO}_{2}$ and $\mathrm{CO}$.

In the subgroup analysis, we examined the age, gender and concurrent comorbid health conditions including hypertension, diabetes, hyperlipidemia and congestive heart failure as potential effect modifiers. Figure 2a shows the associations between PM concentrations and hospitalizations for arrhythmia, stratified by age. The association for both $\mathrm{PM}_{2.5}$ and $\mathrm{PM}_{10}$ were stronger and lasted longer in the elderly. An IQR increase in $\mathrm{PM}_{2.5}$ and $\mathrm{PM}_{10}$ concentrations on lag5 day resulted in $1.01 \%(95 \% \mathrm{CI}, 0.13-$ $1.89 \%$ ) and $1.72 \%$ (95\%CI, $0.65-2.79 \%)$ increases, respectively, in admissions among the elderly, compared with the null or even negative association in adults aged 18-65. The differences between the two groups were statistically

Table 3 Correlation coefficients among air pollutants

\begin{tabular}{llllll}
\hline Variables & $\mathrm{PM}_{2.5}$ & $\mathrm{PM}_{10}$ & $\mathrm{NO}_{2}$ & $\mathrm{SO}_{2}$ & $\mathrm{CO}$ \\
\hline $\mathrm{PM}_{2.5}$ & 1.00 & $0.87^{*}$ & $0.67^{*}$ & $0.61^{*}$ & $0.68^{*}$ \\
$\mathrm{PM}_{10}$ & - & $1.00^{*}$ & $0.64^{*}$ & $0.63^{*}$ & $0.60^{*}$ \\
$\mathrm{NO}_{2}$ & - & - & 1.00 & $0.54^{*}$ & $0.59^{*}$ \\
$\mathrm{SO}_{2}$ & - & - & - & 1.00 & $0.55^{*}$ \\
$\mathrm{CO}$ & - & - & - & - & 1.00 \\
\hline${ }^{*} P<0.001$ & & & & &
\end{tabular}

significant $\left(\mathrm{PM}_{2.5}: p<0.001 ; \mathrm{PM}_{10}: p<0.001\right)$. Analyses revealed a significant association between exposure to air pollutants and hospitalizations for arrhythmia in individuals with diabetes. An IQR increase in $\mathrm{PM}_{2.5}$ and $\mathrm{PM}_{10}$ concentrations on lag4 day resulted in $1.80 \%(95 \% \mathrm{CI}$, $0.28-3.35 \%$ ) and $2.73 \%$ (95\% CI, $0.89-4.59 \%$ ) increases, respectively, in hospitalization for arrhythmia in patients with diabetes, but only a $-0.24 \%(95 \% \mathrm{CI},-0.79-0.32 \%)$ and $0.37 \%(95 \% \mathrm{CI},-0.29-1.05 \%)$ increases in patients without diabetes (Fig. 2b). However, gender and all comorbidities other than diabetes failed to show a noticeable effect modification between the concentration of particle matters and arrhythmia admissions in any lag structures (all $p>0.05$; shown in Additional file 1: Figure S2).

\section{Discussion}

In our study, we took the advantage of a large database of hospital visits collected over 26 large Chinese cities during a two-year time period to examine the association between airborne particle matters and cardiac arrhythmia hospitalization. To the best of our knowledge, this is the first multisite study in China, or even in the Asia, to examine the effects of PMs pollution on arrhythmia. We observed that short-term elevated concentration of $\mathrm{PM}_{2.5}$ and $\mathrm{PM}_{10}$ were significantly associated with increased risk of cardiac arrhythmia hospital admissions. An IQR increase in $\mathrm{PM}_{2.5}$ and $\mathrm{PM}_{10}$ on lag 2 day associated with a $2.09 \%\left(0.44 \%\right.$ for $10 \mu \mathrm{g} / \mathrm{m}^{3}$ increase in $\mathrm{PM}_{2.5}$ ) and $2.33 \%$ (0.30\% for $10 \mu \mathrm{g} / \mathrm{m}^{3}$ increase in $\mathrm{PM}_{10}$ ) increase in admissions for cardiac arrhythmia, respectively. We did not find evidence of effect modification by gender, but we found a stronger and longer lasting effect among aged population and people with diabetes. Other prespecified comorbid health conditions including hypertension, congestive heart failure and hyperlipidemia did not modify the risk.

Panel studies [20,21], which required participants to wear a Holter monitor or implantable cardioverter defibrillators 

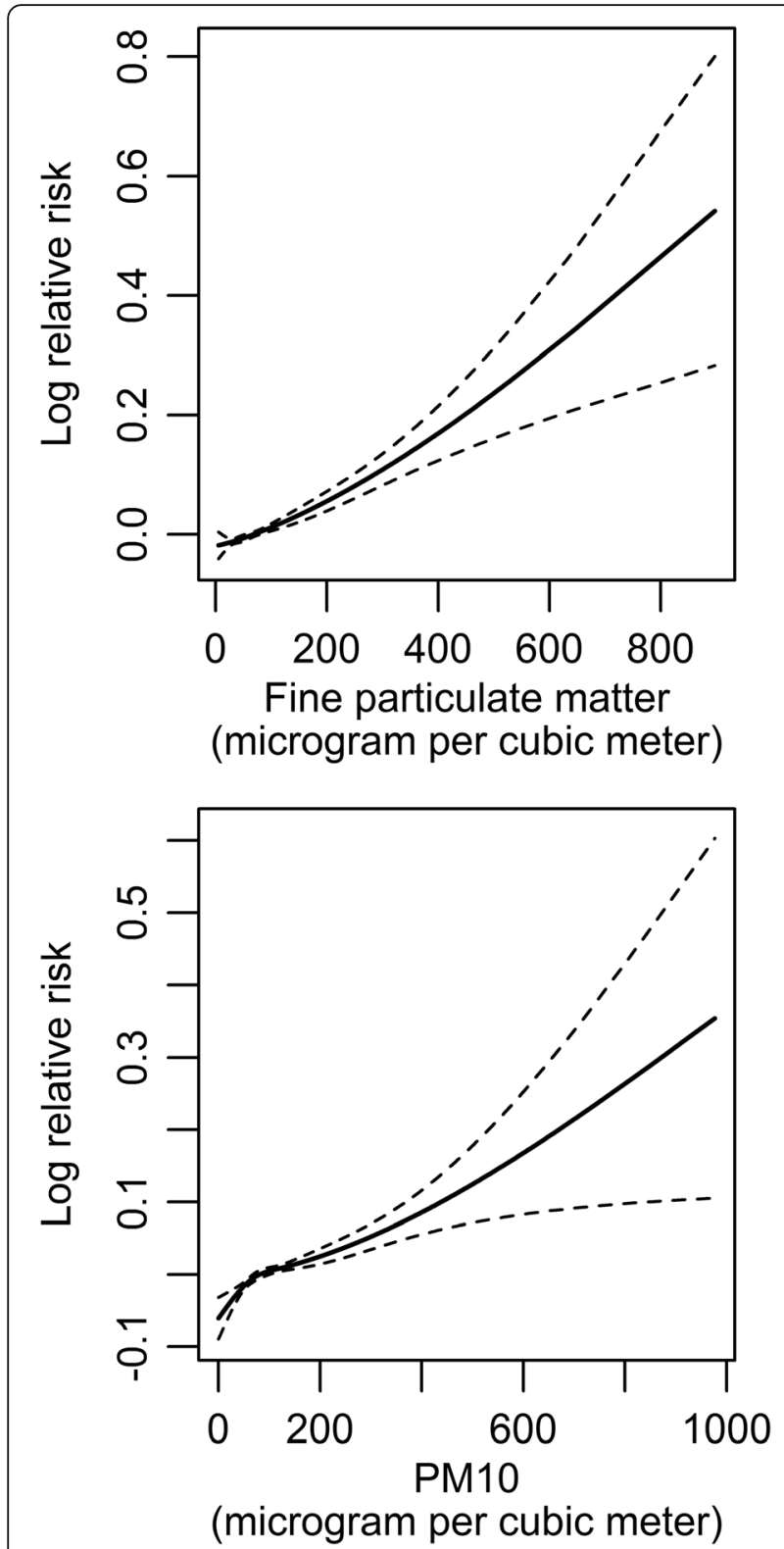

Fig. 1 Dose-response relationship between cardiac arrhythmia hospital admissions in 26 Chinese cities and particle matters concentration (degree of freedom $=3$ ). The $x$-axis of the upper part is the 4-d (lag0-3) moving average concentration of fine particulate matter $\left(\mu \mathrm{g} / \mathrm{m}^{3}\right)$; the $\mathrm{x}$-axis of the lower part is the 5 - $\mathrm{d}$ (lag0-4) moving average concentration of $\mathrm{PM}_{10}\left(\mu \mathrm{g} / \mathrm{m}^{3}\right)$. The $y$-axis is the predicted log (relative risk) after adjusting for the temperature, relative humidity, public holidays and city-level confounders. The solid lines represent the effect estimates and the dashed lines represent $95 \%$ confidence intervals

(ICDs), have confirmed the association between air pollution episodes and cardiac arrhythmia. However, the results from studies exploring the relationship between air pollution and the risk of having arrhythmia-related hospitalization or ER visits among larger and more general populations remain controversial. In Canada [22], a time-series analysis conducted among nearly 400,000 ER visits in seven cities failed to demonstrate the association between arrhythmia and daily PMs concentrations. Another case-crossover study in the US [23] showed atrial fibrillation hospital admission is not increased with short-term elevation in exposure to $\mathrm{PM}_{2.5}$ either. On the contrary, there is a growing body of literature linking cardiac arrhythmia with exposure to airborne PMs and give positive conclusion. Talbott [24] investigated over 7,500,000 hospital admissions for circulatory diseases across seven states in the United States during 2001 to 2008, and demonstrated significant associations between ambient $\mathrm{PM}_{2.5}$ levels, after controlling for temperature and ozone, and arrhythmia hospitalizations, especially in the cooler months. In the UK [10], a large case-crossover study linking daily mean concentrations of air pollutants with three databases, the Myocardial Ischemia National Audit Project (MINAP), Hospital Episode Statistics (HES) and Mortality (Office for National Statistics), involving over 2 million CVD emergency hospital admissions and over 600,000 CVD deaths, demonstrated that $\mathrm{PM}_{2.5}$ is associated with a raised risk of arrhythmia hospitalization and mortality. In East Asia, Ueda [25] conducted a multicity study in Japan and found a significantly positive association between arrhythmia mortality and $\mathrm{PM}_{2.5}$. Agreeing with our finding, two recent studies performed in Taipei $[26,27]$ demonstrated the significant positive association between PM concentration and arrhythmia ER visits or hospital admissions. Recently, a time-series analysis study [13] including 56,940 outpatient visits for cardiac arrhythmia conducted in Shanghai, China, found that a $10 \mu \mathrm{g} / \mathrm{m}^{3}$ increase in the present-day concentration of $\mathrm{PM}_{10}$ corresponded to increase of $0.56 \%$ (95\% CI, 0.42 to $0.70 \%)$ in outpatient arrhythmia visits. The inconsistency in results reported around the world may stem from the different concentration level of ambient particle matters, complex component of the pollutants, population susceptibility and so forth.

We have found that age modified the risk for arrhythmia hospitalization in relation to $\mathrm{PM}_{2.5}$ and $\mathrm{PM}_{10}$ concentration levels. This conclusion was generally consistent with most previous reports. Zhao [13] found that the associations between $\mathrm{PM}_{10}$ and outpatient arrhythmia visits were stronger in elderly participants. In MINAP study [10], the effect of $\mathrm{PM}_{2.5}$ on mortality was higher in those over the age of 70 . The frailty of the elderly is the most likely reason why they show a strong reaction on a high level of PMs concentration. It is plausible that most elderly have higher prevalence of chronic cardiopulmonary diseases, leading to poor health conditions. Therefore, they are more susceptible to the adverse effect of particle matters. However, results concluded from other studies [8, 23] 
Table 4 Percentage change with $95 \% \mathrm{Cl}$ in cardiac arrhythmia admissions associated with an IQR increases in $\mathrm{PM} 2.5\left(47.5 \mu \mathrm{g} / \mathrm{m}^{3}\right)$ and $\mathrm{PM}_{10}\left(76.9 \mathrm{\mu g} / \mathrm{m}^{3}\right)$ concentration for different lag structure

\begin{tabular}{|c|c|c|c|c|c|c|}
\hline \multirow[t]{2}{*}{ Lag Days } & \multicolumn{3}{|l|}{$\mathrm{PM}_{2.5}$} & \multicolumn{3}{|l|}{$\mathrm{PM}_{10}$} \\
\hline & Percentage Change & $95 \% \mathrm{Cl}$ & $p$ value & Percentage Change & $95 \% \mathrm{Cl}$ & $p$ value \\
\hline Lag 0 days & 1.50 & $0.98-2.02$ & $<0.001$ & 1.56 & $0.92-2.19$ & $<0.001$ \\
\hline Lag 1 days & 1.89 & $1.37-2.40$ & $<0.001$ & 1.91 & $1.27-2.55$ & $<0.001$ \\
\hline Lag 2 days & 2.09 & $1.58-2.60$ & $<0.001$ & 2.33 & $1.68-2.97$ & $<0.001$ \\
\hline Lag 3 days & 1.48 & $0.97-2.00$ & $<0.001$ & 2.15 & $1.52-2.79$ & $<0.001$ \\
\hline Lag 4 days & 0.00 & $-0.52-0.52$ & 0.997 & 0.65 & $0.02-1.28$ & 0.043 \\
\hline Lag 5 days & -0.36 & $-0.88-0.16$ & 0.177 & -0.10 & $-0.73-0.54$ & 0.767 \\
\hline Lag $0-2$ days & 2.67 & $2.03-3.31$ & $<0.001$ & 2.92 & $2.11-3.74$ & $<0.001$ \\
\hline Lag 0-3 days & 2.93 & $2.24-3.63$ & $<0.001$ & 3.56 & $2.67-4.46$ & $<0.001$ \\
\hline Lag 0-4 days & 2.67 & $1.91-3.43$ & $<0.001$ & 3.58 & $2.61-4.56$ & $<0.001$ \\
\hline Lag 0-5 days & 2.28 & $1.47-3.09$ & $<0.001$ & 3.22 & $2.19-4.26$ & $<0.001$ \\
\hline
\end{tabular}

$\mathrm{Cl}$ confidence interval, IQR interquartile range. The association was adjusted for temperature, relative humidity, public holidays and city-level confounders

showed weak evidence for effect modification by age groups. Different data source, outcome definition and study design may interpret part of the reason and further studies are needed to clarify this inconsistency.

Evidence from epidemiological studies [28-30] reported that persons with chronic comorbid health conditions may be at increased risk of cardiovascular morbidity and mortality associated with air pollutants levels. Existing diabetes modified the association of particle matters and arrhythmia admissions have been demonstrated in some previous studies. For example, in Park's study [31], persons with ischemic heart disease, hypertension or diabetes appear to be more susceptible to autonomic dysfunction related to $\mathrm{PM}_{2.5}$ exposure. Peel [14], by evaluating over 4 million emergency department visits from 31 hospitals in America, also found the estimated association of arrhythmia in relation to $\mathrm{PM}_{10}$ was substantially higher among patients with hypertension or diabetes than for patients without such comorbid conditions, whereas COPD and congestive heart failure provided little evidence of effect modification. Possible explanation is that exposure to particle matters is associated with reduced heart rate variability, increased C-reactive protein levels and elevated inflammatory markers, which shared the same pathway with diabetes. In contrast, Colais [15] identified a series of chronic conditions and failed to find a clear marker of

Table 5 Estimated odds ratio and 95\% confidence intervals in cardiac arrhythmia admissions associated with air pollutants concentrations on lag 2 day in two-pollutant models

\begin{tabular}{lll}
\hline Variable & $\mathrm{PM}_{2.5}$ & $\mathrm{PM}_{10}$ \\
\hline Adjusted for $\mathrm{NO}_{2}$ & $0.80(0.14-1.47)^{*}$ & $-0.08(-0.91-0.76)$ \\
Adjusted for $\mathrm{SO}_{2}$ & $3.29(2.71-3.87)^{* * *}$ & $3.35(2.62-4.09) * * *$ \\
Adjusted for $\mathrm{CO}$ & $0.95(0.24-1.66)^{* *}$ & $0.27(-0.57-1.11)$ \\
\hline${ }^{*} P<0.05 * * P<0.01{ }^{* * *} P<0.001$ &
\end{tabular}

susceptibility for arrhythmia on the effect of $\mathrm{PM}_{10}$. Bunch [23] observed no additive risk between $\mathrm{PM}_{2.5}$ and atrial fibrillation hospitalization in those with respiratory disease either. Inconsistency of results may derive from factors related to the disease itself. Patients with cardiovascular disease are more likely to reduce exposure to the air pollution and taking antihypertensive or heart rhythm control medications, thus reducing their occurrence of arrhythmia symptom.

Recent studies [32, 33] have provided a limited but growing understanding of possible biological mechanisms. One major hypothesis is the autonomic nerve system dysfunction, which results in increased heart rate and impaired heart rate variability. Such autonomic modulation triggers the onset of premature ventricular contractions and premature atrial contractions, and the lag structures found in most studies indicate a rapid pathway. In patient-based study, Rich [34-36] pointed out the evidence of acute effects $(1 \mathrm{~h})$ of elevated PMs on severe arrhythmias patients wearing ICDs. In large population-based study, Santos [37] examined 3251 arrhythmia ER visits and drew the conclusion that the association between arrhythmia and daily $\mathrm{PM}_{10}$ was acute and limited to the same day of exposure. Zhao [13] also reported the effect of $\mathrm{PM}_{10}$ concentration was limited within the concurrent day by analyzing 56,940 outpatient visits for arrhythmia in Shanghai. In our study, we found the results that both $\mathrm{PM}_{2.5}$ and $\mathrm{PM}_{10}$ had the strongest impact at lag 2 days, which is in line with other previously published studies [10, 26]. One potential explanation for this discrepancy in the different lag structure is that the use of hospital admissions rather than outpatient visits or emergency room visits. Delay in time is existed between symptom onset and hospital admission for further treatment. In consequence, the lag effects of particle matters on cardiac arrhythmia hospital admissions should be interpreted with caution. 


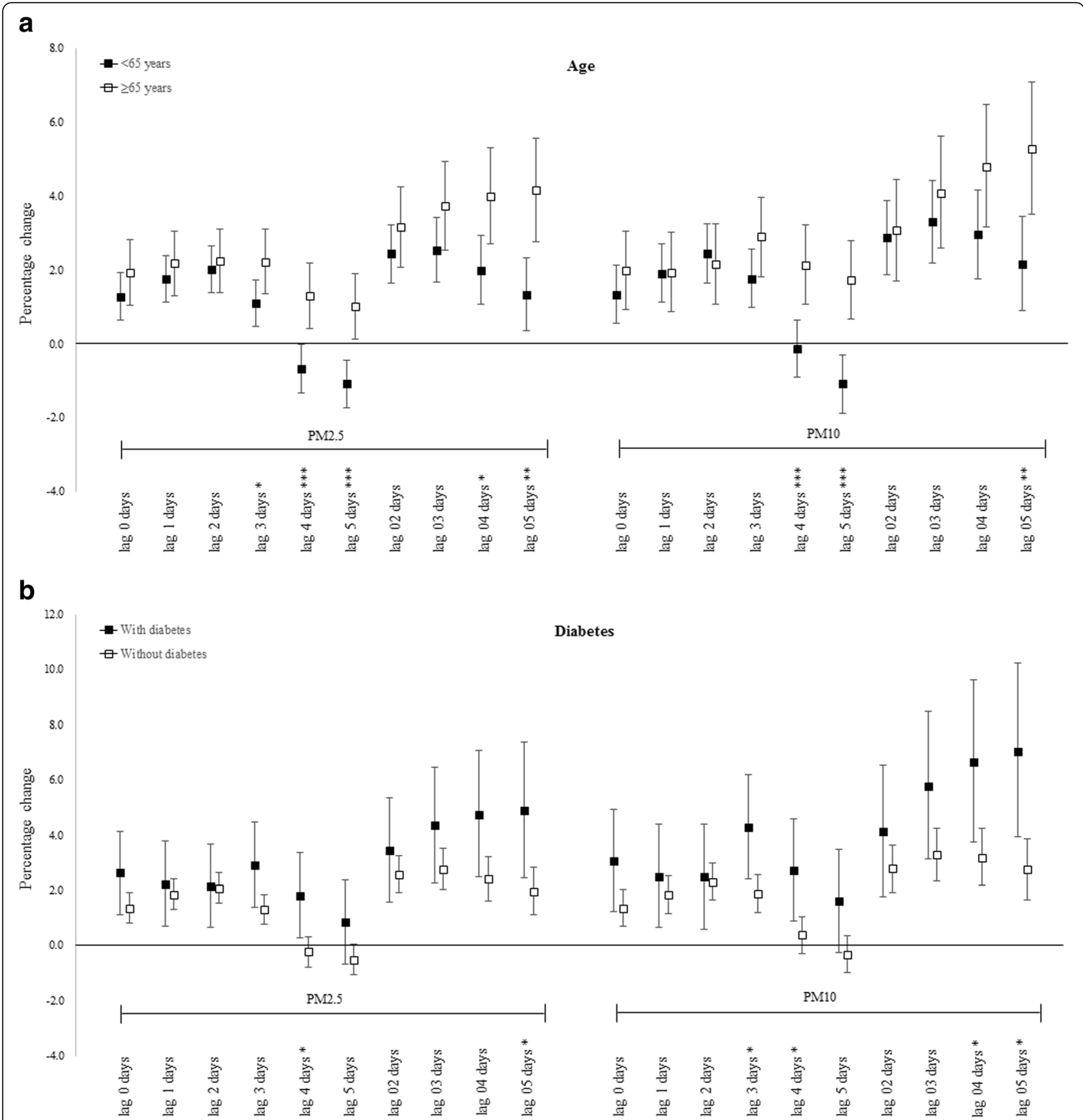

Fig. 2 Percentage change with 95\% confidence interval in cardiac arrhythmia admissions associated with an interquartile range increase in $P_{2.5}$ $\left(47.5 \mu \mathrm{g} / \mathrm{m}^{3}\right)$ and $\mathrm{PM}_{10}\left(76.9 \mu \mathrm{g} / \mathrm{m}^{3}\right)$ concentrations stratified by age $(\mathbf{a})$ and diabetes $(\mathbf{b})$. Note: ${ }^{*} P<0.05{ }^{* *} P<0.01{ }^{* * *} P<0.001$

The strengths of our investigation include the national coverage of a wide range of hospital admissions among 26 Chinese cities. Multicity studies have the advantage of generating more reliable results and tend to be less vulnerable to bias compared with small studies conducted at single site. To our knowledge, this is the first multicity study in China, or even in the Asia, to examine the short-term effects of air pollution on arrhythmia. An additional strength is the ability to detect comorbid health status. By using large amounts of clinical information, potential effect modifiers could be identified.

Some limitations need to be addressed. Firstly, as in most previous epidemiological studies, we have used the averaged monitoring results across various stations as the proxy for the population exposure level. This might bring about exposure measurement errors because personal exposure depends on a number of issues, such as daily outdoor activities, the use of air cleaner, location of residence 
and so forth. Another limitation of our study is the use of data from hospital admissions instead of outpatient visits. Some kinds of arrhythmia often show no symptoms. Mild cases who suffered palpitations or feeling a pause between heartbeats may choose to take medication at home or to visit their family doctors. Besides, due to the inclusion of top-ranked hospitals only, the characteristics of severity of illness and socio-demographic conditions of the cases included in our analysis might be different from those patients admitted into lower ranked hospitals. Therefore, the generalizability of our results should be interpreted with caution. Thirdly, comorbid health conditions were evaluated merely based on concurrent hospital discharge records rather than including diagnoses from previous visits, potentially reducing the sensitivity of comorbid conditions assessment and leading to misclassify of the subgroup. For this reason, the effect difference of airborne particle matters between groups with and without specific secondary conditions may tend to null. However, some studies [30] showed little or no difference in using concurrent or previous records when evaluating comorbidity. Moreover, two-pollutant models were applied to examine the robustness of the associations between PMs and cardiac arrhythmia. However, the collinearity among the pollutants added uncertainty to the interpretation of the results and limited our ability to isolate the independent effects of PMs on cardiac arrhythmia. Therefore, the results of two-pollutant models should be interpreted with caution. Finally, due to the limit information, the inability to differentiate all subtypes of cardiac arrhythmia is another limitation in our study. Nevertheless, both ventricular and supraventricular kinds of arrhythmia have been demonstrated [37] its susceptibility to the effect of air pollutants. Further studies are needed to confirm whether there is modification effect across different subtype of cardiac arrhythmia or not.

\section{Conclusion}

In summary, by using a considerably larger sample of patients than previous studies in developing world, our study provided robust evidence that an increased risk of arrhythmia admissions was associated with the level of $\mathrm{PM}_{2.5}$ and $\mathrm{PM}_{10}$ among 26 large cities in China. Evidence of effect modification by age and comorbid diabetes was observed in response to PM levels. Future studies with tightly controlled exposure level, in addition to long-term observational studies are needed to help elucidate the effect in the long run.

\section{Additional file}

Additional file 1: Figure S1. Locations of 26 Chinese cities and their average daily PM2.5 concentration during the study period. 26 Chinese cities included Harbin $(71 \mu \mathrm{g} / \mathrm{m} 3)$, Changchun $(65 \mu \mathrm{g} / \mathrm{m} 3)$, Shenyang
(72 $\mu \mathrm{g} / \mathrm{m} 3)$, Dalian(50 $\mu \mathrm{g} / \mathrm{m} 3)$, Beijing $(82 \mu \mathrm{g} / \mathrm{m} 3)$, Tianjin $(78 \mu \mathrm{g} / \mathrm{m} 3)$, Shijiazhuang (106 $\mu \mathrm{g} / \mathrm{m} 3)$, Jinan $(90 \mu \mathrm{g} / \mathrm{m} 3)$, Zhengzhou $(91 \mu \mathrm{g} / \mathrm{m} 3)$, Xi'an (67 $\mu \mathrm{g} / \mathrm{m} 3)$, Lanzhou (54 $\mu \mathrm{g} / \mathrm{m} 3)$, Yinchuan $(48 \mu \mathrm{g} / \mathrm{m} 3)$, Xining $(55 \mu \mathrm{g} / \mathrm{m} 3)$, Urumchi $(64 \mu \mathrm{g} / \mathrm{m} 3)$, Chengdu $(67 \mu \mathrm{g} / \mathrm{m} 3)$, Chongqing $(59 \mu \mathrm{g} / \mathrm{m} 3)$, Wuhan $(75 \mu \mathrm{g} / \mathrm{m} 3)$, Changsha $(67 \mu \mathrm{g} / \mathrm{m} 3)$, Nanchang $(46 \mu \mathrm{g} /$ $\mathrm{m3})$, Nanjing $(65 \mu \mathrm{g} / \mathrm{m} 3)$, Shanghai $(53 \mu \mathrm{g} / \mathrm{m} 3)$, Hangzhou $(58 \mu \mathrm{g} / \mathrm{m} 3)$, Kunming $(31 \mu \mathrm{g} / \mathrm{m} 3)$, Nanning $(45 \mu \mathrm{g} / \mathrm{m} 3)$, Guangzhou $(43 \mu \mathrm{g} / \mathrm{m} 3)$ and Fuzhou $(30 \mu \mathrm{g} / \mathrm{m} 3)$. Figure S2. Percentage change with $95 \%$ confidence interval in arrhythmia admissions associated with an interquartile range increase in PM2.5 $(47.5 \mu \mathrm{g} / \mathrm{m} 3)$ and PM10 $(76.9 \mu \mathrm{g} / \mathrm{m} 3)$ concentrations stratified by gender (A), hypertension (B), hyperlipidemia (C) and congestive heart failure (D). Table S1. Basic information and numbers of the monitoring sites in each study city. (DOCX $834 \mathrm{~kb}$ )

\section{Abbreviations}

Cl: Confidence interval; CO: Carbon monoxide; DALY: Disability-adjusted life year; HSR: Hospitalization summary report; ICD-10: International Classification of Diseases, 10th Revision; IQR: Interquartile range; $\mathrm{NO}_{2}$ : Nitrogen dioxides; OR: Odds ratio; PM: Particle matter; $\mathrm{PM}_{2.5}, \mathrm{PM}_{10}$ : Particulate matter $\leq 2.5-\mu \mathrm{m}$ (or $<10-\mu \mathrm{m}$ ) in diameter; $\mathrm{SO}_{2}$ : Sulfur dioxide

\section{Availability of data and materials}

Weather data are available from: http://data.cma.cn/site/index.html; air pollutants data are available from:http://106.37.208.233:20035/; hospital admission data are obtained from the National Hospital Performance Project conducted by the National Healthcare Data Center of China. They have local system to access data for scientific use, however it has not deposited in publicly available repositories. Therefore, it is available from the corresponding author on reasonable request.

\section{Authors' contributions}

DC and JZ had full access to all the data in the study and take responsibility for the integrity of the data and the accuracy of the analysis. DC and JZ were responsible for the study concept and design. QZ and $\mathrm{HL}$ conducted the research; HL acquired environmental data, provided analytic support and data interpretation; QZ analyzed the data and wrote the manuscript. All authors read and approved the final manuscript.

\section{Ethics approval and consent to participate}

Data were collected for administrative purposes, included no identifiable private information, and determined as not acquired from human subjects.

Consent for publication

Not applicable.

\section{Competing interests}

The authors declare that they have no competing interests.

\section{Publisher's Note}

Springer Nature remains neutral with regard to jurisdictional claims in published maps and institutional affiliations.

\section{Author details}

${ }^{1}$ Department of Epidemiology and Biostatistics, School of Public Health, Peking University, No.38 Xueyuan Road, Haidian District, Beijing 100191, China. ${ }^{2}$ Medical Informatics Center, Peking University, No.38 Xueyuan Road, Haidian District, Beijing 100191, China. 'Department of Neurology, Peking University People's Hospital, No.11 South Xizhimen Street, Xicheng District, Beijing 100044, China.

Received: 9 November 2017 Accepted: 29 June 2018

Published online: 16 July 2018

References

1. Cohen AJ, Brauer M, Burnett R, Anderson HR, Frostad J, Estep K, Balakrishnan K, Brunekreef B, Dandona L, Dandona R, et al. Estimates and 25-year trends of the global burden of disease attributable to ambient air pollution: an analysis of data from the global burden of diseases study 2015. Lancet. 2017;389(10082):1907-18.

2. Forouzanfar MH, Alexander $\mathrm{L}$, Anderson HR, Bachman VF, Biryukov S, Brauer M, Burnett R, Casey D, Coates MM, Cohen A, et al. Global, regional, and 
national comparative risk assessment of 79 behavioural, environmental and occupational, and metabolic risks or clusters of risks in 188 countries, 19902013: a systematic analysis for the global burden of disease study 2013. Lancet (London, England). 2015;386(10010):2287-323.

3. Murakoshi N, Aonuma K. Epidemiology of arrhythmias and sudden cardiac death in Asia. Circ J. 2013;77(10):2419-31.

4. Le Tertre A, Medina S, Samoli E, Forsberg B, Michelozzi P, Boumghar A, Vonk JM, Bellini A, Atkinson R, Ayres JG, et al. Short-term effects of particulate air pollution on cardiovascular diseases in eight European cities. J Epidemiol Community Health. 2002;56(10):773-9.

5. Burnett RT, Smith-Doiron M, Stieb D, Cakmak S, Brook JR. Effects of particulate and gaseous air pollution on cardiorespiratory hospitalizations. Arch Environ Health. 1999:54(2):130-9.

6. Dockery DW. Epidemiologic evidence of cardiovascular effects of particulate air pollution. Environ Health Perspect. 2001;109(Suppl 4):483-6.

7. Samet JM, Zeger SL, Dominici F, Curriero F, Coursac I, Dockery DW, Schwartz J, Zanobetti A. The National Morbidity, mortality, and air pollution study. Part II: morbidity and mortality from air pollution in the United States. Res Rep Health Eff Inst. 2000;94(Pt 2):5-70. discussion 71-79

8. Barnett AG, Williams GM, Schwartz J, Best TL, Neller AH, Petroeschevsky AL, Simpson RW. The effects of air pollution on hospitalizations for cardiovascular disease in elderly people in Australian and New Zealand cities. Environ Health Perspect. 2006;114(7):1018-23.

9. Chiu HF, Tsai SS, Weng HH, Yang CY. Short-term effects of fine particulate air pollution on emergency room visits for cardiac arrhythmias: a casecrossover study in Taipei. J Toxicol Environ Health A. 2013;76(10):614-23.

10. Milojevic A, Wilkinson P, Armstrong B, Bhaskaran K, Smeeth L, Hajat S. Shortterm effects of air pollution on a range of cardiovascular events in England and Wales: case-crossover analysis of the MINAP database, hospital admissions and mortality. Heart. 2014;100(14):1093-8.

11. Halonen Jl, Lanki T, Yli-Tuomi T, Tiittanen P, Kulmala M, Pekkanen J. Particulate air pollution and acute cardiorespiratory hospital admissions and mortality among the elderly. Epidemiology. 2009;20(1):143-53.

12. Song X, Liu Y, Hu Y, Zhao X, Tian J, Ding G, Wang S. Short-Term Exposure to Air Pollution and Cardiac Arrhythmia: A Meta-Analysis and Systematic Review. Int J Environ Res Public Health. 2016;13(7):642-653.

13. Zhao A, Chen R, Kuang $X$, Kan H. Ambient air pollution and daily outpatient visits for cardiac arrhythmia in shanghai, China. J Epidemiol. 2014;24(4):321-6.

14. Peel JL, Metzger KB, Klein M, Flanders WD, Mulholland JA, Tolbert PE. Ambient air pollution and cardiovascular emergency department visits in potentially sensitive groups. Am J Epidemiol. 2007;165(6):625-33.

15. Colais P, Faustini A, Stafoggia M, Berti G, Bisanti L, Cadum E, Cernigliaro A, Mallone S, Pacelli B, Serinelli M, et al. Particulate air pollution and hospital admissions for cardiac diseases in potentially sensitive subgroups. Epidemiology. 2012;23(3):473-81.

16. Janes H, Sheppard L, Lumley T. Case-crossover analyses of air pollution exposure data: referent selection strategies and their implications for bias. Epidemiology. 2005;16(6):717-26.

17. Liu H, Tian $Y, X u Y$, Zhang J. Ambient particulate matter concentrations and hospitalization for stroke in 26 Chinese cities: a case-crossover study. Stroke. 2017:48(8):2052-9.

18. Goldberg MS, Gasparrini A, Armstrong B, Valois MF. The short-term influence of temperature on daily mortality in the temperate climate of Montreal, Canada. Environ Res. 2011;111(6):853-60.

19. Altman DG, Bland JM. Interaction revisited: the difference between two estimates. BMJ (Clinical research ed). 2003;326(7382):219.

20. Pieters N, Plusquin M, Cox B, Kicinski M, Vangronsveld J, Nawrot TS. An epidemiological appraisal of the association between heart rate variability and particulate air pollution: a meta-analysis. Heart. 2012;98(15):1127-35.

21. Peters A, Liu E, Verrier RL, Schwartz J, Gold DR, Mittleman M, Baliff J, Oh JA, Allen G, Monahan K, et al. Air pollution and incidence of cardiac arrhythmia. Epidemiology. 2000;11(1):11-7.

22. Stieb DM, Szyszkowicz M, Rowe BH, Leech JA. Air pollution and emergency department visits for cardiac and respiratory conditions: a multi-city timeseries analysis. Environ Health. 2009;8:25.

23. Bunch TJ, Horne BD, Asirvatham SJ, Day JD, Crandall BG, Weiss JP, Osborn JS, Anderson JL, Muhlestein JB, Lappe DL, et al. Atrial fibrillation hospitalization is not increased with short-term elevations in exposure to fine particulate air pollution. Pacing Clin Electrophysiol. 2011;34(11):1475-9.
24. Talbott EO, Rager JR, Benson S, Brink LA, Bilonick RA, Wu C. A case-crossover analysis of the impact of PM(2.5) on cardiovascular disease hospitalizations for selected CDC tracking states. Environ Res. 2014;134:455-65.

25. Ueda $\mathrm{K}$, Nitta $\mathrm{H}$, Ono M. Effects of fine particulate matter on daily mortality for specific heart diseases in Japan. Circ J. 2009;73(7):1248-54.

26. Chang CC, Chen PS, Yang CY. Short-term effects of fine particulate air pollution on hospital admissions for cardiovascular diseases: a case-crossover study in a tropical city. J Toxicol Environ Health A. 2015;78(4):267-77.

27. Tsai S-S, Chiu H-F, Wu T-N, Yang C-Y. Air pollution and emergency room visits for cardiac arrhythmia in a subtropical city: Taipei, Taiwan. Inhal Toxicol. 2009:21(13):1113-8.

28. Bateson TF, Schwartz J. Who is sensitive to the effects of particulate air pollution on mortality? A case-crossover analysis of effect modifiers. Epidemiology. 2004;15(2):143-9.

29. O'Neill MS, Veves A, Zanobetti A, Sarnat JA, Gold DR, Economides PA, Horton ES, Schwartz J. Diabetes enhances vulnerability to particulate air pollution-associated impairment in vascular reactivity and endothelial function. Circulation. 2005;111(22):2913-20.

30. Zanobetti A, Schwartz J, Gold D. Are there sensitive subgroups for the effects of airborne particles? Environ Health Perspect. 2000;108(9):841-5.

31. Park SK, O'Neill MS, Vokonas PS, Sparrow D, Schwartz J. Effects of air pollution on heart rate variability: the VA normative aging study. Environ Health Perspect. 2005;113(3):304-9.

32. Pope CA 3rd, Hansen ML, Long RW, Nielsen KR, Eatough NL, Wilson WE, Eatough DJ. Ambient particulate air pollution, heart rate variability, and blood markers of inflammation in a panel of elderly subjects. Environ Health Perspect. 2004;112(3):339-45.

33. Huikuri HV, Castellanos A, Myerburg RJ. Sudden death due to cardiac arrhythmias. N Engl J Med. 2001;345(20):1473-82.

34. Rich DQ, Schwartz J, Mittleman MA, Link M, Luttmann-Gibson H, Catalano PJ, Speizer FE, Dockery DW. Association of short-term ambient air pollution concentrations and ventricular arrhythmias. Am J Epidemiol. 2005;161(12): 1123-32.

35. Rich DQ, Mittleman MA, Link MS, Schwartz J, Luttmann-Gibson H, Catalano PJ, Speizer FE, Gold DR, Dockery DW. Increased risk of paroxysmal atrial fibrillation episodes associated with acute increases in ambient air pollution. Environ Health Perspect. 2006:114(1):120-3.

36. Rich DQ, Kim MH, Turner JR, Mittleman MA, Schwartz J, Catalano PJ, Dockery DW. Association of ventricular arrhythmias detected by implantable cardioverter defibrillator and ambient air pollutants in the St Louis, Missouri metropolitan area. Occup Environ Med. 2006;63(9):591-6.

37. Santos UP, Terra-Filho M, Lin CA, Pereira LA, Vieira TC, Saldiva PH, Braga AL. Cardiac arrhythmia emergency room visits and environmental air pollution in Sao Paulo, Brazil. J Epidemiol Community Health. 2008;62(3):267-72.

\section{Ready to submit your research? Choose BMC and benefit from:}

- fast, convenient online submission

- thorough peer review by experienced researchers in your field

- rapid publication on acceptance

- support for research data, including large and complex data types

- gold Open Access which fosters wider collaboration and increased citations

- maximum visibility for your research: over $100 \mathrm{M}$ website views per year

At BMC, research is always in progress.

Learn more biomedcentral.com/submissions 